Article

\title{
Extracts, Anthocyanins and Procyanidins from Aronia melanocarpa as Radical Scavengers and Enzyme Inhibitors
}

\author{
Marie Bräunlich ${ }^{1}{ }^{*}$, Rune Slimestad ${ }^{2}$, Helle Wangensteen ${ }^{1}$, Cato Brede ${ }^{3}$, Karl E. Malterud ${ }^{1}$ \\ and Hilde Barsett ${ }^{1}$
}

1 School of Pharmacy, Department of Pharmaceutical Chemistry, University of Oslo, P.O. Box 1068, Blindern, N-0316 Oslo, Norway; E-Mails: helle.wangensteen@ farmasi.uio.no (H.W.);

k.e.malterud@farmasi.uio.no (K.E.M.); hilde.barsett@farmasi.uio.no (H.B.)

2 PlantChem, Særheim Research Center, N-4353 Klepp station, Norway;

E-Mail: rune@plantchem.com

3 Department of Medical Biochemistry, Stavanger University Hospital, N-4068 Stavanger, Norway; E-Mail: cabr@sir.no

* Author to whom correspondence should be addressed; E-Mail: p.m.braunlich@ farmasi.uio.no; Tel.: +47-22-85-65-64; Fax: +47-22-85-75-05.

Received: 15 January 2013; in revised form: 2 February 2013 / Accepted: 15 February 2013 /

Published: 4 March 2013

\begin{abstract}
Extracts, subfractions, isolated anthocyanins and isolated procyanidins B2, B5 and $\mathrm{C} 1$ from the berries and bark of Aronia melanocarpa were investigated for their antioxidant and enzyme inhibitory activities. Four different bioassays were used, namely scavenging of the diphenylpicrylhydrazyl (DPPH) radical, inhibition of 15-lipoxygenase (15-LO), inhibition of xanthine oxidase (XO) and inhibition of $\alpha$-glucosidase. Among the anthocyanins, cyanidin 3-arabinoside possessed the strongest and cyanidin 3-xyloside the weakest radical scavenging and enzyme inhibitory activity. These effects seem to be influenced by the sugar units linked to the anthocyanidin. Subfractions enriched in procyanidins were found to be potent $\alpha$-glucosidase inhibitors; they possessed high radical scavenging properties, strong inhibitory activity towards 15 -LO and moderate inhibitory activity towards XO. Trimeric procyanidin $\mathrm{C} 1$ showed higher activity in the biological assays compared to the dimeric procyanidins B2 and B5. This study suggests that different polyphenolic compounds of $A$. melanocarpa can have beneficial effects in reducing blood glucose levels due to inhibition of $\alpha$-glucosidase and may have a potential to alleviate oxidative stress.
\end{abstract}


Keywords: Aronia melanocarpa; anthocyanins; procyanidins; DPPH; 15-lipoxygenase; xanthine oxidase; $\alpha$-glucosidase

\section{Introduction}

Aronia, Aronia melanocarpa (Michx.) Elliott, syn. Photinia melanocarpa (Michx.) K. R. Robertson and J. B. Phipps, sometimes called black chokeberry, belongs to the Rosaceae family and is cultivated as a decorative shrub, as a source of berries for juices, wines and jams and as a rich source of natural food colorants [1,2]. In recent years, black chokeberries have gained popularity due to their high content of polyphenols with antioxidant activity [3]. In fact, they possess the highest antioxidant activity among berries and other fruits investigated so far as measured with the oxygen radical scavenging capacity (ORAC) assay [2,4]. The Aronia berries contain high levels of flavonoids, mostly anthocyanins and proanthocyanidins. The formation of free radicals is strongly associated with lipid peroxidation and has also been implicated in the development of a variety of diseases, including cellular aging, mutagenesis, inflammation, carcinogenesis, coronary heart disease and diabetes [5]. Accumulated evidence has suggested that diabetic patients are under oxidative stress, with an imbalance between the free radical generating and radical scavenging capacities [6-11]. 15-Lipoxygenase (15-LO) and xanthine oxidase (XO) are peroxidative and prooxidative enzymes, respectively, and sources of reactive oxygen species (ROS) in vascular cells [12,13]. An overproduction of ROS may be involved in endothelial dysfunction. Thus, substances that inhibit the production of ROS could have a positive effect on cardiovascular function. It has been suggested that A. melanocarpa fruit juice and its anthocyanins might be useful in the prevention and control of diabetes mellitus type II and diabetes associated complications [14,15]. $\alpha$-Glucosidase, which is a membrane-bound enzyme located at the epithelium of the small intestine, plays a vital role in digestion of carbohydrates, as it catalyzes the cleavage of glucose from disaccharides and oligosaccharides. It might be possible to prevent the onset of diabetes by controlling postprandial hyperglycemia through the inhibition of $\alpha$-glucosidase and $\alpha$-amylase activities, resulting in a delay of carbohydrate digestion to absorbable monosaccharide [16]. Studies have revealed that anthocyanins potentially inhibit intestinal $\alpha$-glucosidase, and Adisakwattana et al. [16] reported that cyanidin 3-rutinoside retards absorption of carbohydrates by that mechanism of action. To our knowledge, no systematic investigation on chokeberry anthocyanins and procyanidins as radical scavengers, lipoxygenase inhibitors, xanthine oxidase inhibitors and $\alpha$-glucosidase inhibitors has been reported previously.

The present paper reports in vitro antioxidant activity of extracts, subfractions, anthocyanins and procyanidins isolated from $A$. melanocarpa measured by scavenging of 1,1-diphenyl-2-picrylhydrazyl (DPPH) radical and inhibition of the enzymes 15-LO and XO. Furthermore, the polyphenol-rich extracts were tested for their ability to inhibit $\alpha$-glucosidase. 


\section{Experimental Section}

\subsection{Plant Material}

Aronia berries, A. melanocarpa (Michx.) Elliott var. Moscow, were harvested at Særheim, Klepp, Norway $\left(58^{\circ} 47^{\prime} \mathrm{N}, 5^{\circ} 41^{\prime} \mathrm{E}\right)$ in August 2010. The berries were kept at $-20{ }^{\circ} \mathrm{C}$ until extraction. A voucher specimen (MB201201) is deposited in the Pharmacognosy section, School of Pharmacy, University of Oslo, Norway. Bark, as a source of procyanidins, was sampled from the same plants. Branches with a diameter of 1-2 cm were chosen, and the bark was carefully removed. In total $1500 \mathrm{~g}$ fresh weight (FW) was sampled, giving $732 \mathrm{~g}$ dry weight (DW) upon lyophilization. The plant material was cut in pieces and kept at $-20{ }^{\circ} \mathrm{C}$ until extraction.

\subsection{Chemicals}

Diphenylpicrylhydrazyl (DPPH) radical, linoleic acid, 15-LO from soybeans, hypoxanthine, XO from bovine milk, $\alpha$-glucosidase from baker's yeast, 4-nitrophenyl $\alpha$-D-glucopyranoside (PNP-G), quercetin, acarbose, sodium potassium phosphate, benzyl mercaptan, trifluoroacetic acid (TFA), dimethyl sulfoxide (DMSO), ethyl acetate (EtOAc), dichloromethane (DCM), acetone, ethanol (EtOH) and methanol $(\mathrm{MeOH})$ were purchased from Sigma-Aldrich (St. Louis, MO, USA). Procyanidin B2 and B5 reference compounds were obtained from Plant Polyphenols LLC (Boyce, LA, USA). All other reagents were of the highest purity available.

\subsection{Extraction and Fractionation}

Aronia berries (5.5 kg FW) were freeze-dried, pulverized and extracted with DCM (5 L) followed by $\mathrm{EtOH}(4.5 \mathrm{~L})$ in a Soxhlet apparatus. The plant residue was further extracted by stirring with $3 \times 3 \mathrm{~L} 50 \% \mathrm{EtOH}$ at $70{ }^{\circ} \mathrm{C}$ for $2 \mathrm{~h}$. All extracts were concentrated in vacuo, yielding $26 \mathrm{~g}, 250 \mathrm{~g}$ and $80 \mathrm{~g}$, respectively. The $50 \% \mathrm{EtOH}$ extract $(2.5 \mathrm{~g})$ was fractionated on an Amberlite XAD-7HP ( $3 \times 30 \mathrm{~cm}$; Sigma-Aldrich, St. Louis, MO, USA) column by elution with $400 \mathrm{~mL}$ water followed by $300 \mathrm{~mL} \mathrm{MeOH}, 200 \mathrm{~mL}$ 0.1\% TFA in $\mathrm{MeOH}$ and $200 \mathrm{~mL}$ acetone-water (70:30). The procedure was repeated until a total amount of $10 \mathrm{~g}$ had been applied on the column. The $\mathrm{MeOH}$ fraction (Amb-MeOH) was concentrated to dryness in vacuo, and a yield of $2 \mathrm{~g}$ was obtained. Of this, $920 \mathrm{mg}$ was dissolved and further fractionated over Sephadex LH-20 $(3 \times 30 \mathrm{~cm}$; GE Healthcare, Uppsala, Sweden) with $\mathrm{MeOH}$-water (from 20:80 to 100:0) as eluent. This gave three subfractions, namely Seph I (418 mg; eluted with 20\% MeOH), Seph II (44 mg; 40\% MeOH) and Seph III (278 mg; $100 \% \mathrm{MeOH})$.

\subsection{Isolation of Anthocyanins}

In parallel to the work described in section 2.3., Aronia berries ( $2 \mathrm{~kg} \mathrm{FW})$ were extracted by maceration with $2 \times 6 \mathrm{~L} \mathrm{MeOH}(0.5 \% \mathrm{TFA}$ v/v) for $24 \mathrm{~h}$ at ambient temperature and most of the solvent evaporated in vacuo. The concentrated water-enriched extract $(0.5 \mathrm{~L})$ was partitioned against EtOAc $(4 \times 0.5 \mathrm{~L})$. The organic phase was discarded, whereas the water-phase was concentrated and purified on a bed of Amberlite XAD-7HP $(5 \times 50 \mathrm{~cm}$ column) by use of water until the eluate had 
$\mathrm{pH} 6$ followed by elution with $1 \mathrm{~L} \mathrm{MeOH}(0.5 \%$ TFA). The anthocyanin-enriched extract was then eluted through a Sephadex LH-20 column $(5 \times 100 \mathrm{~cm})$ by use of a step gradient of $15 \%(3 \mathrm{~L})$ and $30 \%$ (4 L) $\mathrm{MeOH}(0.1 \%$ TFA v/v). Fractions of $200 \mathrm{~mL}$ were collected and analyzed by HPLC. Purity acceptance was defined as the analyte peak area representing $>96 \%$ of total area as detected at 520 and $280 \mathrm{~nm}$. Overlapping fractions were combined and reapplied to the same column, and five column runs gave approximately $200 \mathrm{mg}$ cyanidin 3-galactoside (1), $200 \mathrm{mg}$ cyanidin 3-arabinoside (3) and $20 \mathrm{mg}$ cyanidin 3-xyloside (4). Only minute amounts of pure cyanidin 3-glucoside (2) were obtained.

\subsection{Isolation of Procyanidins}

Instead of using berries as a source of oligomeric procyanidins, bark was chosen, as this is a richer source and as this gave a simpler polyphenolic composition (e.g., no anthocyanins). A bark sample of $466 \mathrm{~g} \mathrm{DW}$ was extracted with $2 \times 10 \mathrm{~L} 70 \%$ acetone at room temperature for $24 \mathrm{~h}$. After concentration in vacuo, the $0.5 \mathrm{~L}$ extract was defatted with $2 \times 0.5 \mathrm{~L}$ DCM. The organic phase, which contained $6.4 \mathrm{~g}$ dry matter, was discarded. The sample was further partitioned against $3 \times 0.5 \mathrm{~L}$ EtOAc, and the organic phase was concentrated in vacuo, followed by lyophilization. The EtOAc part yielded $7.8 \mathrm{~g} \mathrm{DW}$. Of this, $2 \mathrm{~g}$ was applied to a $5 \times 100 \mathrm{~cm}$ column of Sephadex LH-20, and separation was achieved by use of a step gradient of 50\% (2 L), 80\% (3 L) and 100\% (10 L) MeOH. Fractions of $1 \mathrm{~L}$ were collected and analyzed by thin layer chromatography (TLC) and HPLC. About $200 \mathrm{mg}$ procyanidin B2 (5), $20 \mathrm{mg}$ B5 (6) and $50 \mathrm{mg}$ of C1 (7) were obtained. Purity acceptance was defined as the analyte peak area comprising $>96 \%$ of total chromatographic area at $280 \mathrm{~nm}$ and at fluorescence detection (see section 2.6.).

\subsection{Analysis}

\subsubsection{TLC}

TLC analysis of procyanidins was performed with silica gel on polyethylene terephthalate (PET)-foils (Sigma-Aldrich, St. Louis, MO, USA) in the mobile phase system EtOAc-HCOOH-HOAc- $\mathrm{H}_{2} \mathrm{O}$ (75:2:3:20 v/v), upper layer. Mobile-phase distance was $10 \mathrm{~cm}$. Spraying with vanillic acid-HCl-MeOH $(1: 4: 100, w / v / v)$, followed by heating with a hair dryer, was used for spot detection.

\subsubsection{HPLC}

An Agilent 1100-system, Agilent Technologies (Santa Clara, CA, USA), was used for the purity check of the individual anthocyanins, and they were identified by comparison with in-house reference compounds [17]. Separation took place over an Eclipse XDB-C8 $(4.6 \times 150 \mathrm{~mm}, 5 \mu \mathrm{m})$ column (Agilent Technologies, Santa Clara, CA, USA) by use of a binary solvent system consisting of (A) $\mathrm{HCOOH}-\mathrm{H}_{2} \mathrm{O}(1: 9 \mathrm{v} / \mathrm{v})$ and (B) $\mathrm{HCOOH}-\mathrm{MeOH}-\mathrm{H}_{2} \mathrm{O}(10: 50: 40$, v/v). The gradient (B in A) was isocratic, with $0 \% \mathrm{~B}$ for $2 \mathrm{~min}$, linear from $0 \%$ to $70 \%$ in $18 \mathrm{~min}$, from $70 \%$ to $100 \%$ for the next 2 min, from $100 \%$ to $0 \%$ in $2 \mathrm{~min}$, followed by recondition of the column for $2 \mathrm{~min}$. All HPLC samples were filtered through a $13 \mathrm{~mm}$ syringe filter (Nylon $0.45 \mu \mathrm{m}$, VWR International, Radnor, PA, USA) prior to injection. The flow rate was $0.8 \mathrm{~mL} / \mathrm{min}, 10 \mu \mathrm{L}$ samples were injected on the column and separation took place at $30{ }^{\circ} \mathrm{C}$. Chromatograms were obtained at 280 and $520 \mathrm{~nm}$. 
HPLC analyses of procyanidins were performed on the same instrument and column with the solvent system (A) $0.05 \%$ TFA and (B) $0.05 \%$ TFA in MeCN. The gradient (B in A) was $5 \%$ (10 min), from $5 \%$ to $15 \%$ (10 $\mathrm{min}$ ), from $15 \%$ to $20 \%$ (10 $\mathrm{min}$ ), from $20 \%$ to $100 \%$ (6 $\mathrm{min}$ ), from $100 \%$ to $5 \%$ (4 min) and finally recondition of the column for $2 \mathrm{~min}$. The flow rate was $0.5 \mathrm{~mL} / \mathrm{min}$, column temperature $30{ }^{\circ} \mathrm{C}$, and aliquots of $10 \mu \mathrm{L}$ were injected. Fluorescence detection was achieved with excitation at $276 \mathrm{~nm}$ and emission at $316 \mathrm{~nm}$ (HP 1046A detector, Hewlett-Packard, Palo Alto, CA, USA), whereas UV-absorbance was detected at $280 \mathrm{~nm}$.

\subsubsection{UV Measurements}

For UV measurements used in bioassay, a Biochrom Libra S32 PC (Biochrom Ltd, Cambridge, UK) was employed.

\subsubsection{Thiolysis}

About $10 \mathrm{mg}$ crude extract was dissolved in 5\% benzyl mercaptan in $\mathrm{MeOH}$ containing $1.1 \% \mathrm{HCl}$ (v/v) and kept at $50{ }^{\circ} \mathrm{C}$ for $30 \mathrm{~min}$. Procyanidin B1 and B2 were used as standards, with terminal units catechin and epicatechin, respectively. The products following the thiolysis reactions were analyzed by the method described for procyanidins on HPLC.

\subsubsection{Mass Spectrometry}

Crude extracts of berries (MeOH-extract) and bark (70\% acetone), together with the isolated procyanidins, were further characterized by liquid chromatography coupled with mass spectrometry (LC-MS) using a nanoAcquity ultra performance liquid chromatography (UPLC) (Waters, Milford, MA, USA) coupled with a quadrupole time-of-flight (QTOF) micro hybrid mass spectrometer (Waters) equipped with nanoLockspray mass calibration. Reversed phase separations were achieved on a $600 \mathrm{~mm}$ long and $0.05 \mathrm{~mm}$ ID in-house prepared porous polymer monolithic column. The mobile phase consisted of (A) $0.1 \%$ formic acid and $0.05 \%$ ammonium hydroxide in water mixed with (B) $0.1 \%$ formic acid in acetonitrile. Injection of $2 \mu \mathrm{L}$ sample diluted in water was done with a high flow rate $(3 \mu \mathrm{L} / \mathrm{min})$ for $5 \mathrm{~min}$ on a short trap column $(50 \mathrm{~mm})$ of a similar type as the analytical column, using a mobile phase composition of $1 \% \mathrm{~B}$. A linear gradient from 0 to $10 \mathrm{~min}$ was performed by varying B from $2 \%$ to $10 \%$ at an elevated flow rate of $400 \mathrm{~nL} / \mathrm{min}$, in order to compensate for the large dwell volume. Then, the flow rate was reduced to $200 \mathrm{~nL} / \mathrm{min}$ and the compounds eluted with a gradient reaching $30 \%$ of B at $30 \mathrm{~min}$ and $80 \%$ of B at $40 \mathrm{~min}$. Electrospray ionization in the positive mode (ESI+) was used with a capillary voltage at $3 \mathrm{kV}$ and a cone voltage at $35 \mathrm{~V}$. Mass spectra were collected in the $m / z$ range of 200-2000 with $1 \mathrm{~s}$ scantime. Instrument control, data acquisition and data processing were done by using MassLynx 4.1 software (Waters, Milford, MA, USA).

\subsubsection{NMR}

${ }^{1} \mathrm{H}$ and ${ }^{13} \mathrm{C}$ nuclear magnetic resonance (NMR) spectroscopy of extract and fractions were conducted on Varian Gemini 200 (Varian, Palo Alto, CA, USA), Bruker DPX 300 or Bruker AVII 400 
(Bruker, Rheinstetten, Germany) instruments and performed in $\mathrm{CDCl}_{3}$ or $\mathrm{CD}_{3} \mathrm{OD}$ with tetramethylsilane (TMS) as an internal standard.

\subsection{DPPH Radical Scavenging}

Scavenging activity towards the DPPH radical was carried out as previously described [18]. Briefly, to $2.95 \mathrm{~mL}$ of a methanolic solution of DPPH $\left(\mathrm{A}_{517} 1.0\right), 50 \mu \mathrm{L}$ of the test compound (dissolved in DMSO or $\mathrm{MeOH}$ ) was added. The mixture was stirred, and the decrease in UV absorbance at $517 \mathrm{~nm}$ was measured over a period of $5 \mathrm{~min}$. Percent radical scavenging was calculated as $100 \times\left(\mathrm{A}_{\text {start }}-\mathrm{A}_{\text {end }}\right) /\left(\mathrm{A}_{\text {start }}\right)$, where $\mathrm{A}_{\text {start }}$ is the absorbance before addition of the test compound and $A_{\text {end }}$ is the absorbance value after 5 min of reaction time. Values were corrected for absorbance of the test substances. Quercetin was used as a positive control.

\subsection{Inhibition of 15-Lipoxygenase (15-LO)}

Soybean lipoxygenase was used to measure inhibition of 15-LO. To a solution of linoleic acid $(134 \mu \mathrm{M})$ in borate buffer $(0.2 \mathrm{M}, \mathrm{pH} 9.00,2.90 \mathrm{~mL})$ was added $50 \mu \mathrm{L}$ of test substance dissolved in DMSO or MeOH or (for blanks) DMSO or $\mathrm{MeOH}$ alone. A solution of $15-\mathrm{LO}$ in $50 \mu \mathrm{L}$ borate buffer $(10,000 \mathrm{U} / \mathrm{mL})$ was added, and the increase in absorbance at $234 \mathrm{~nm}$ from 30 to $90 \mathrm{~s}$ after addition was measured. Percent enzyme inhibition was calculated as $100 \times\left[\left(\Delta \mathrm{A}_{1}-\Delta \mathrm{A}_{2}\right) / \Delta \mathrm{A}_{1}\right]$, where $\Delta \mathrm{A}_{1}$ and $\Delta \mathrm{A}_{2}$ are values for increase in $\mathrm{A}_{234}$ for sample without test substance and with test substance, respectively [18]. Quercetin was used as a positive control.

\subsection{Inhibition of Xanthine Oxidase (XO)}

The XO inhibitory activity with hypoxanthine as the substrate was measured spectrophotometrically based on the procedure of Noro et al. [19], with some modifications. The assay mixture consisting of $50 \mu \mathrm{L}$ of test compound (dissolved in DMSO or $\mathrm{MeOH}$ ) or (for blanks) DMSO or MeOH alone, $1.85 \mathrm{~mL}$ of $50 \mathrm{mM}$ sodium-potassium phosphate buffer $(\mathrm{pH}=7.5)$ and $100 \mu \mathrm{L}$ of enzyme solution $(1.8 \mathrm{U} / \mathrm{mL}$ in $50 \mathrm{mM}$ sodium-potassium phosphate buffer, $\mathrm{pH}=7.5$ ) was prepared immediately before use. Substrate solution $(1.0 \mathrm{~mL}, 20 \mu \mathrm{g} / \mathrm{mL}$ hypoxanthine in distilled water) was added. The mixture was stirred, and the increase in absorbance at $290 \mathrm{~nm}$ was measured over a period of $5 \mathrm{~min}$. Percent enzyme inhibition was calculated as $100 \times\left[\left(\Delta \mathrm{A}_{1}-\Delta \mathrm{A}_{2}\right) / \Delta \mathrm{A}_{1}\right]$, where $\Delta \mathrm{A}_{1}$ and $\Delta \mathrm{A}_{2}$ are values for the increase in $\mathrm{A}_{290}$ for the sample without test substance and with test substance, respectively. Quercetin was used as a positive control.

\subsection{0. $\alpha$-Glucosidase Inhibitory Activity}

The $\alpha$-glucosidase inhibitory activity was determined by a slight modification of the procedure reported by Matsui et al. [20]. The enzyme solution was set at $800 \mathrm{mU} / \mathrm{mL}$ of $\alpha$-glucosidase in a $50 \mathrm{mM}$ phosphate buffer $(\mathrm{pH}=7.0$ ) containing $100 \mathrm{mM}$ sodium chloride. For each assay, $20 \mu \mathrm{L}$ of the test solution in DMSO or $\mathrm{MeOH}$ and $80 \mu \mathrm{L}$ of the enzyme solution were preincubated at $37{ }^{\circ} \mathrm{C}$ for $5 \mathrm{~min}$. The reaction was started by adding $1.9 \mathrm{~mL}$ of substrate solution ( $0.7 \mathrm{mM} \mathrm{PNP}-\mathrm{G}$ in the buffer), and the solution was then incubated at $37^{\circ} \mathrm{C}$ for $15 \mathrm{~min}$. After the reaction had been stopped by adding 
$2.0 \mathrm{~mL}$ of a $0.5 \mathrm{M}$ Tris solution, the absorbance of PNP released from PNP-G at $400 \mathrm{~nm}$ was measured. Percent enzyme inhibition was calculated as $100 \times\left(A_{B}-A_{S}\right) /\left(A_{B}\right)$, where $A_{B}$ and $A_{S}$ represent the absorbance of the blank and sample, respectively. Acarbose was used as a positive control.

\subsection{Statistics}

Samples for DPPH, 15-LO, XO and $\alpha$-glucosidase assays were analyzed in triplicate and results are given as averages \pm SD. Student's $t$ test was used for statistical evaluation and $p<0.05$ was considered statistically significant.

\section{Results and Discussion}

\subsection{Extraction and Chemical Characterization}

In chokeberry fruits, anthocyanins constitute the second largest group of phenolic compounds [1]. The anthocyanins in A. melanocarpa are mainly a mixture of four cyanidin glycosides: 3-galactoside, 3-glucoside, 3-arabinoside and 3-xyloside, of which cyanidin 3-galactoside is the main one (Figure 1) [17]. In order to isolate the major anthocyanins from Aronia berries, extraction with $\mathrm{MeOH}$ containing TFA was performed, since direct alcoholic extractions provide very poor yield, not keeping anthocyanins in the stable flavylium cationic form. The anthocyanins (1-4) were isolated as pure compounds, and their structures are shown in Figure 2. Their chromatographic and spectral characteristics were in agreement with previous observations [17]. Aronia berries were also extracted as shown in Figure 3.

Figure 1. High-performance liquid chromatography (HPLC) chromatogram of the isolated anthocyanins: cyanidin 3-galactoside (1), cyanidin 3-glucoside (2), cyanidin 3-arabinoside (3) and cyanidin 3-xyloside (4).

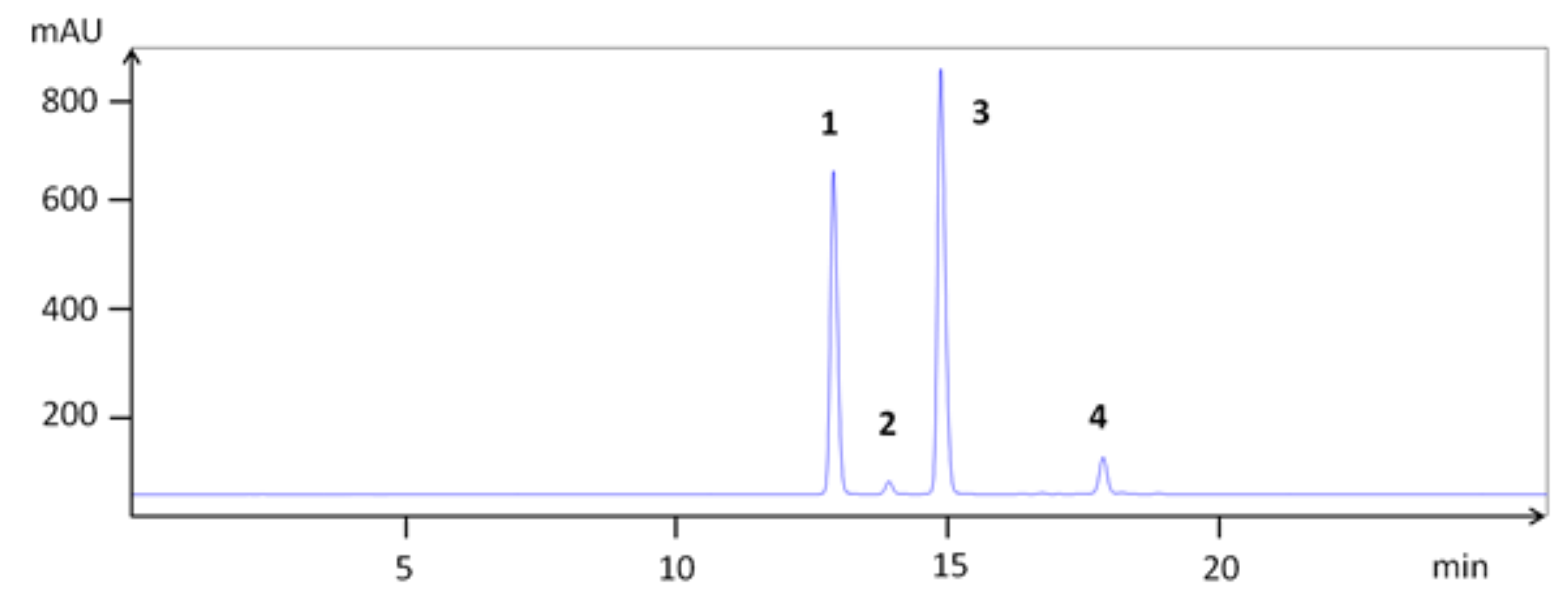


Figure 2. Chemical structures of compounds isolated from berries and bark of Aronia.<smiles></smiles>

1. $\mathrm{R}=$ galactose: Cyanidin 3-galactoside

2. $\mathrm{R}=$ glucose: Cyanidin 3-glucoside

3. $\mathrm{R}=$ arabinose: Cyanidin 3 -arabinoside

4. $\mathrm{R}=$ xylose: $\quad$ Cyanidin 3-xyloside<smiles>Oc1cc(O)c2c(c1)O[C@H](c1ccc(O)c(O)c1)[C@H](O)[C@H]2c1c(O)cc(O)c2c1O[C@H](c1ccc(O)c(O)c1)[C@H](O)C2</smiles>

5. Procyanidin B2<smiles>Oc1cc(O)c2c(c1)O[C@H](c1ccc(O)c(O)c1)[C@H](O)[C@H]2c1c(O)cc2c(c1O)C[C@@H](O)[C@H](c1ccc(O)c(O)c1)O2</smiles>

7. Procyanidin $\mathrm{Cl}$ 
Figure 3. Procedure for extraction and fractionation from berries of Aronia. Anthocyanins (section 2.4.) and procyanidins (section 2.5.) were extracted by different procedures.

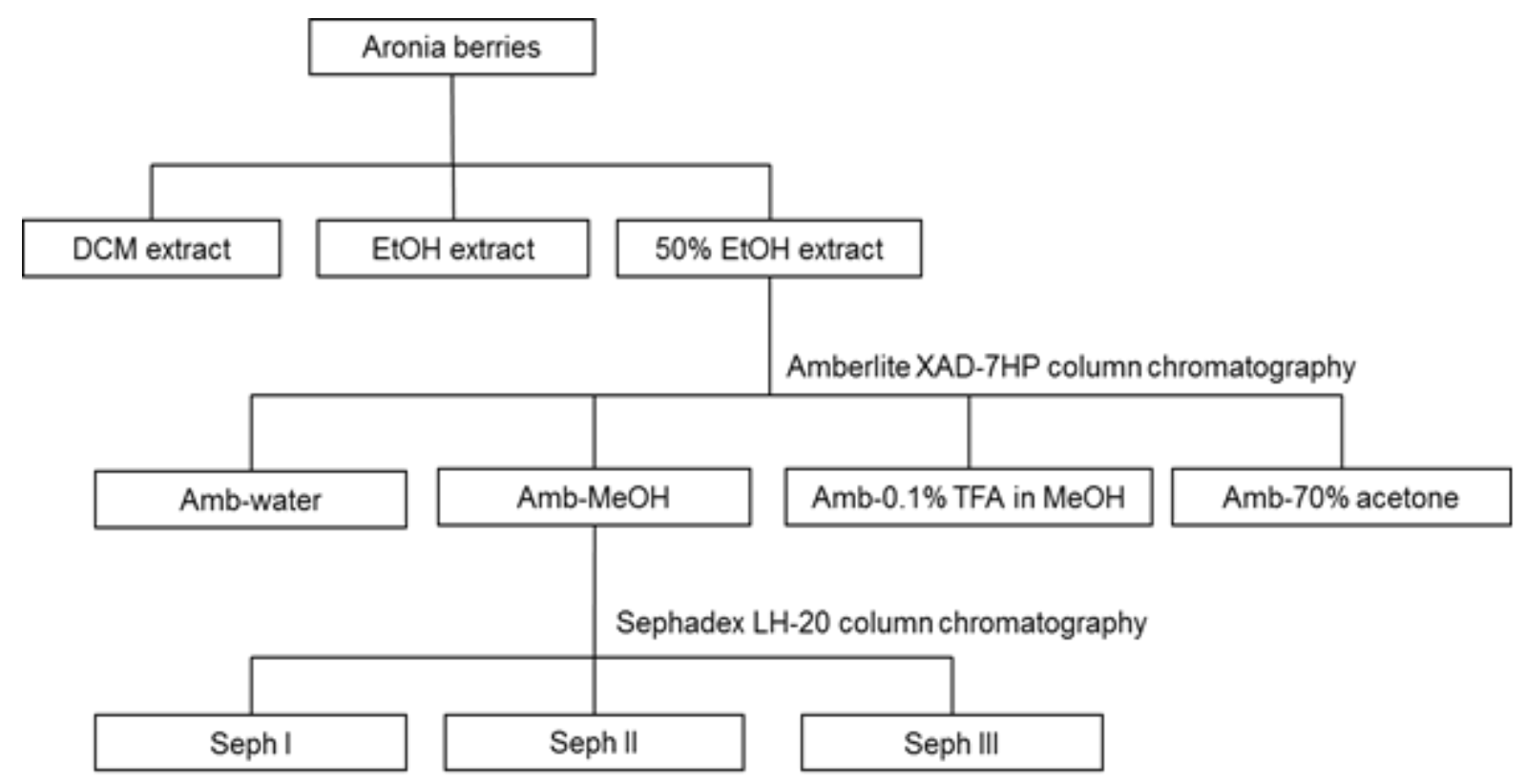

${ }^{1} \mathrm{H}$ NMR and ${ }^{13} \mathrm{C}$ NMR analysis revealed that proanthocyanidins were present in the $50 \%$ EtOH extract $\left(70{ }^{\circ} \mathrm{C}\right)$. Subfractions of the extract were further shown to consist mainly of proanthocyanidins with epicatechin stereochemistry ( ${ }^{1} \mathrm{H}$ NMR: B-ring protons: ca. $6.8 \mathrm{ppm}$, A-ring protons: ca. $6.0 \mathrm{ppm}$ [21]; ${ }^{13}$ C NMR: C-2 at ca. 77 ppm, no signals at 80-82 ppm [22]). However, fraction Seph II (eluted with $40 \% \mathrm{MeOH})$ did not contain proanthocyanidins.

In parallel to this procedure, dimeric (5 and 6) and trimeric (7) procyanidins (Figure 2) were isolated from Aronia bark. The bark was found to be a simpler source for isolation of procyanidins compared to berries, as the complexity with respect to total phenolic structures was lower (e.g., no anthocyanins). The concentration of procyanidins was higher in Aronia bark, as well. It has previously been shown that procyanidins B2, B5 and C1 are present both in bark and berries of the Aronia plant [2]. The isolated compounds were identified by co-chromatography against authentic substances (B2 and B5) and by mass spectrometry (Figure 4, Table 1). Thiolysis of crude extracts revealed that epicatechin was the major monomeric unit of the procyanidins, both as the starter and extender unit. Only minor amounts of catechin were detected. This might be due to epimerization of epicatechin. 
Figure 4. HPLC chromatogram of a bark extract of Aronia melanocarpa showing procyanidins B2 (5), B5 (6) and C1 (7).

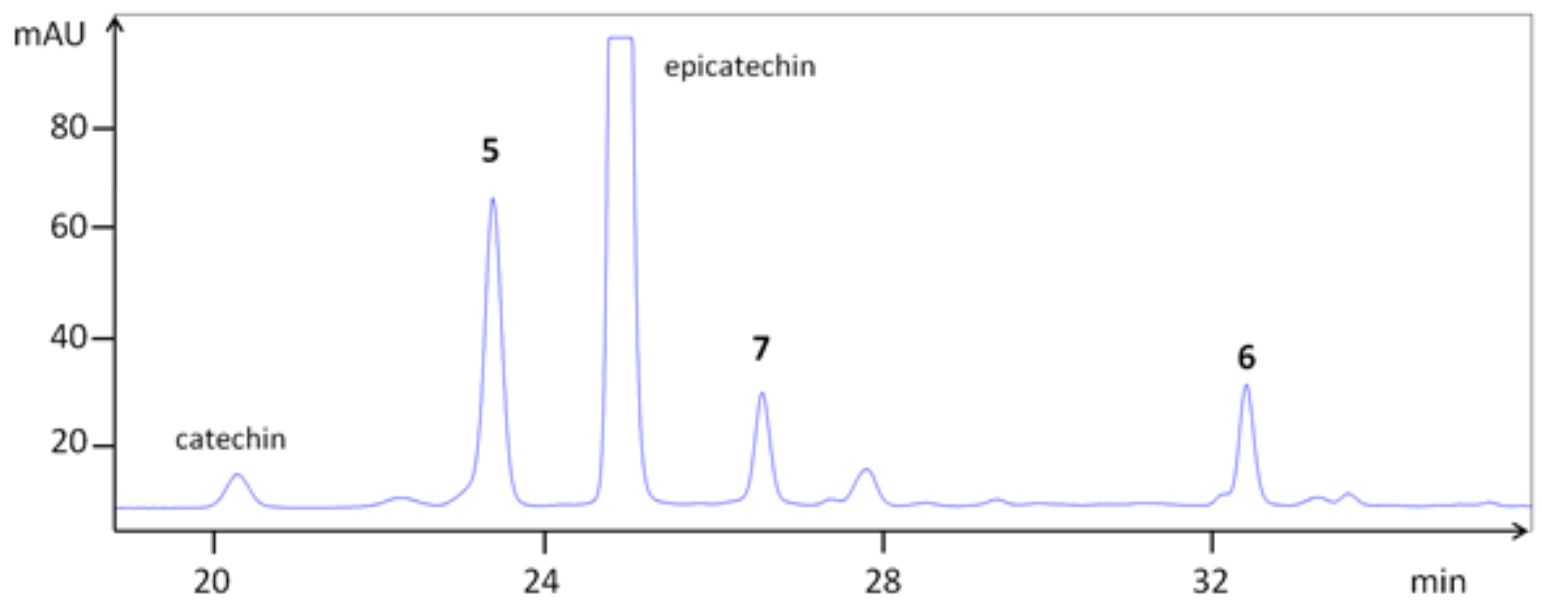

Table 1. Chromatographic and spectral characterization of anthocyanins and procyanidins from Aronia melanocarpa.

\begin{tabular}{|c|c|c|c|c|c|c|}
\hline & Compounds & $\begin{array}{l}\text { TLC } \\
\text { rR }_{F}\end{array}$ & $\begin{array}{l}\text { HPLC } \\
t_{\mathrm{R}}(\min ) \\
\end{array}$ & $\begin{array}{l}\text { LCMS } \\
t_{\mathrm{R}}(\mathrm{min}) \\
\end{array}$ & {$[\mathbf{M}+\mathbf{H}]^{+}$} & $\begin{array}{l}\text { Fragments } \\
\text { (amu) }\end{array}$ \\
\hline 1 & cyanidin 3-galactoside & & 12.9 & 22.0 & 449.104 & 287.044 \\
\hline 2 & cyanidin 3 -glucoside & & 13.9 & 22.2 & 449.102 & 287.044 \\
\hline 3 & cyanidin 3-arabinoside & & 15.0 & 22.7 & 419.084 & 287.039 \\
\hline \multirow[t]{2}{*}{4} & cyanidin 3 -xyloside & & 17.8 & 24.3 & 419.085 & 287.040 \\
\hline & epicatechin & 79 & 25.1 & 28.5 & 291.078 & \\
\hline 5 & 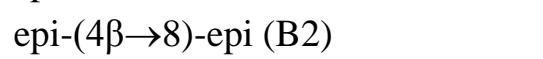 & 58 & 23.4 & 29.9 & 579.157 & 291.078 \\
\hline 6 & 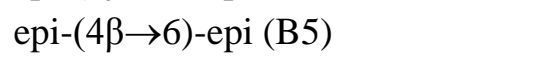 & 67 & 32.5 & 35.6 & 579.168 & 291.084 \\
\hline 7 & epi- $(4 \beta \rightarrow 8)$-ерi- $(4 \beta \rightarrow 8)$-epi $(\mathrm{C} 1)$ & 51 & 26.7 & 32.7 & 867.216 & $579.143,291.080$ \\
\hline
\end{tabular}

It has previously been reported that polymeric procyanidins, composed predominantly of (-)-epicatechin units, are the major class of polyphenolic compounds in chokeberry [1,3]. The degree of polymerization of procyanidins varies from 2 to 23 units in the fruits, with clear domination of $>$ decamers fraction and with flavan-3-ol subunits connected mainly with C4-C6 and C4-C8 bonds (B-type bonds) [1]. Free epicatechin is also present in black chokeberries, although its concentration is significantly lower in comparison with polymeric procyanidins. Previous investigations have reported anthocyanin concentrations of $0.6 \%-2 \%$ (DW) and procyanidin concentrations of $4 \%-5 \%$ (DW) in Aronia berries [2].

\subsection{Biochemical Activities}

The activity of crude extracts, subfractions and isolated compounds as DPPH scavengers, 15-LO and $\alpha$-glucosidase inhibitors is shown in Table 2. The 50\% EtOH crude extract showed high radical scavenging activity, and the effect was strengthened in the subfractions enriched in procyanidins (Amb-MeOH, Seph I and Seph III fraction). Trimeric procyanidin (compound 7) showed higher radical scavenging activity than the dimeric procyanidins (compound $\mathbf{5}$ and $\mathbf{6}$ ). The radical scavenging 
ability of compound $\mathbf{5}$ and $\mathbf{7}$ is in good accordance with the literature [23,24]. Compound $\mathbf{6}$, however, seems to be previously unreported as a DPPH scavenger. Anthocyanins also possessed high radical scavenging capacity. $\mathrm{IC}_{50}$ values could not be established for compounds $\mathbf{1 - 4}$, since an increase in sample concentration resulted in a strongly colored mixture that influenced the UV-absorbance. For this reason, percent scavenging at a sample concentration of $10.4 \mu \mathrm{g} / \mathrm{mL}$ was measured. Compound 1-3 were found to have the strongest DPPH scavenging capacity among the anthocyanins. The activity of compound 4 differed from the activity of the other anthocyanins, having the weakest DPPH radical scavenging capacity. Hence, sugar units linked to the anthocyanidin might have an influence on the biological effect. The radical scavenging activity of the anthocyanins is in fair accordance with previous investigations, although compound $\mathbf{3}$ has been reported to be slightly less active than $\mathbf{2}$ [25].

Table 2. Scavenging of the diphenylpicrylhydrazyl (DPPH) radical, 15-LO and $\alpha$-glucosidase inhibitory activity of Aronia extracts, fractions and compounds.

\begin{tabular}{|c|c|c|c|}
\hline Material & $\begin{array}{c}\mathrm{DPPH} \\
\mathrm{IC}_{50}{ }^{a}(\mu \mathrm{g} / \mathrm{mL})^{\# /} \\
\text { \% scavenging at } 10.4 \mu \mathrm{g} / \mathrm{mL}^{\wedge}\end{array}$ & $\begin{array}{l}\alpha \text {-Glucosidase } \\
\mathrm{IC}_{50}{ }^{a}(\mu \mathrm{g} / \mathrm{mL})\end{array}$ & $\begin{array}{c}\text { 15-Lipoxygenase } \\
\mathrm{IC}_{50}{ }^{a}(\mu \mathrm{g} / \mathrm{mL})\end{array}$ \\
\hline DCM & $>167^{\#}$ & Inactive & $>83$ \\
\hline $\mathrm{EtOH}$ & $>167^{\#}$ & Inactive & $>83$ \\
\hline $50 \% \mathrm{EtOH}$ & $25.0 \pm 5.0^{\#}$ & $3.5 \pm 0.1$ & $>83$ \\
\hline Amb-MeOH & $3.8 \pm 0.2^{\#}$ & $0.55 \pm 0.01$ & $56.7 \pm 0.7$ \\
\hline Seph I & $3.1 \pm 0.5^{\#}$ & $\mathrm{nt}^{b}$ & $30.3 \pm 0.7$ \\
\hline Seph II & $12.0 \pm 2.8^{\#}$ & $\mathrm{nt}^{b}$ & $91.0 \pm 4.8$ \\
\hline Seph III & $4.0 \pm 0.5^{\#}$ & $\mathrm{nt}^{b}$ & $33.0 \pm 2.0$ \\
\hline Compound 1 & $39.0 \pm 2.9^{\wedge}$ & $1.54 \pm 0.1$ & $71.5 \pm 1.8$ \\
\hline Compound 2 & $37.0 \pm 0.9^{\wedge}$ & $0.87 \pm 0.2$ & $73.3 \pm 2.1$ \\
\hline Compound $\mathbf{3}$ & $40.0 \pm 0.4^{\wedge}$ & $0.37 \pm 0.08$ & $58.7 \pm 2.5$ \\
\hline Compound 4 & $25.0 \pm 5.0^{\wedge}$ & $5.5 \pm 1.6$ & $>83$ \\
\hline Compound $\mathbf{5}$ & $4.7 \pm 0.3^{\#}$ & $4.7 \pm 0.2$ & $65.1 \pm 2.6$ \\
\hline Compound 6 & $5.2 \pm 0.1^{\#}$ & $5.5 \pm 0.1$ & $72.3 \pm 5.7$ \\
\hline Compound 7 & $3.2 \pm 0.1^{\#}$ & $3.8 \pm 0.2$ & $57.6 \pm 2.0$ \\
\hline Quercetin (control) & $3.0 \pm 0.2^{\#}$ & $\mathrm{nt}^{b}$ & $26.0 \pm 2.0$ \\
\hline Acarbose (control) & $\mathrm{nt}^{b}$ & $130.0 \pm 20.0$ & $\mathrm{nt}^{b}$ \\
\hline
\end{tabular}

The 50\% EtOH crude extract, the Amb-MeOH fraction and compound 1-7 showed high activity in the $\alpha$-glucosidase assay compared to the positive control acarbose, an anti-diabetic drug. In addition, the purified anthocyanins were more active than the isolated dimeric and trimeric procyanidins (compound 5-7). It is known that some anthocyanin extracts from plants exert a potent in vitro $\alpha$-glucosidase inhibitory effect [26]. Also, McDougall et al. [27] found that the extent of inhibition of $\alpha$-glucosidase is related to the anthocyanin content in different soft fruits. Among the anthocyanins, compounds $\mathbf{2}$ and $\mathbf{3}$ showed the highest activity and compound $\mathbf{4}$ the lowest. The activity of substance 1 is consistent with the literature [28]. To our knowledge, $\alpha$-glucosidase inhibitory activity of substances 2-7 has not been reported previously. Ma et al. [29] showed that the $\alpha$-glucosidase inhibitory activity of flavan-3-ol monomer and oligomers increased as the molecular weight increased, 
with a significant difference in potency between the strongest ones (pentamers) and the weakest one (monomer). The Amb-MeOH fraction appeared to contain polymeric procyanidins, and this could explain its strong effect towards $\alpha$-glucosidase. Trimeric procyanidin (compound 7) possessed stronger $\alpha$-glucosidase inhibitory activity compared to the dimeric procyanidins (compound 5 and $\mathbf{6}$ ). It appeared that the activity increased with increasing molecular weight, which is in good accordance with previously reported results [29]. For the anthocyanins, we found a highly significant correlation between $\alpha$-glucosidase inhibition and DPPH radical scavenging activity $\left(p<0.005, R^{2}=0.997\right.$ ). This is in good accordance with the literature [6]. For the crude extracts, the Amb-MeOH fraction and the procyanidins, the correlation was not significant. The Sephadex LH-20 fractions (Seph I-III) could not be tested for $\alpha$-glucosidase inhibitory activity due to lack of material.

The Amb-MeOH fraction showed high inhibitory activity toward 15-LO, and the effect was strengthened in the subfractions enriched in procyanidins (Seph I and Seph III fraction). Differences in activity between isolated anthocyanins and procyanidins were relatively small. Both groups of compounds possessed high 15-LO inhibitory ability, with compound 3 and 7 being the most active ones. The 15-LO inhibition of $\mathbf{1}, \mathbf{2}, \mathbf{3}$ and $\mathbf{7}$ is in accordance with previous investigations [23,30]. Substances 4, $\mathbf{5}$ and $\mathbf{6}$, however, seem to be previously unreported as 15-LO inhibitors.

The activity of crude extracts, subfractions and isolated compounds as XO inhibitors is presented in Table 3.

Table 3. Xanthine oxidase inhibitory activity of extracts, fractions and compounds from Aronia berries.

\begin{tabular}{cc}
\hline Material & \% inhibition at a concentration of $\mathbf{4 2} \mathbf{\mu g} / \mathbf{m L}$ \\
\hline DCM & Inactive \\
EtOH & Inactive \\
$50 \%$ EtOH & Inactive \\
Amb-MeOH & $26.3 \pm 3.4$ \\
Seph I & $32.2 \pm 7.8$ \\
Seph II & $19.9 \pm 7.6$ \\
Seph III & $46.5 \pm 5.9$ \\
Compound $\mathbf{5}$ & $12.7 \pm 2.8$ \\
Compound $\mathbf{6}$ & $6.6 \pm 0.7$ \\
Compound $\mathbf{7}$ & $15.5 \pm 1.5$ \\
\hline & \% inhibition at a concentration of $\mathbf{1 7} \boldsymbol{\mu g} / \mathbf{m L}$ \\
\hline Compound $\mathbf{1}$ & $11.9 \pm 4.4$ \\
Compound $\mathbf{2}$ & $20.9 \pm 3.4$ \\
Compound $\mathbf{3}$ & $39.1 \pm 2.1$ \\
Compound $\mathbf{4}$ & $11.4 \pm 2.8$ \\
\hline
\end{tabular}

The Amb-MeOH fraction possessed modest activity in the $\mathrm{XO}$ assay, and the effect was again strengthened in the subfractions enriched in procyanidins (Seph I and Seph III fraction). Due to absorbance above the upper detection limit of the spectrometer (sample concentrations $>42 \mu \mathrm{g} / \mathrm{mL}$ for crude extracts, subfractions and procyanidins and sample concentrations $>17 \mu \mathrm{g} / \mathrm{mL}$ for anthocyanins), higher concentrations of extracts and compounds could not be tested. Compound 7 was the strongest inhibitor among the isolated procyanidins, and compound $\mathbf{3}$ was the strongest among the anthocyanins. 
However, all were less efficient than the positive control quercetin $\left(\mathrm{IC}_{50} 0.6 \pm 0.1 \mu \mathrm{g} / \mathrm{mL}\right.$ ). To our knowledge, inhibition of XO of Aronia berry extracts and substances 1, 3, 4 and $\mathbf{6}$ have not been reported previously. The $50 \% \mathrm{EtOH}$ crude extract showed no inhibitory activity toward XO.

Both the DCM and the EtOH crude extract were inactive as DPPH radical scavengers, 15-LO, XO and $\alpha$-glucosidase inhibitors. Among the isolated anthocyanins, compound 3 possessed the strongest and compound 4 the weakest radical scavenging and enzyme inhibitory activity. These effects seem to be influenced by the sugar units linked to the anthocyanidin. Trimeric procyanidin (compound 7) showed higher activity in the biological assays compared to the dimeric procyanidins (compounds 5 and 6), and it appeared that the activity increased with increasing molecular weight. In addition, there was a difference in activity between the two dimeric procyanidins, with compound $\mathbf{5}$ being the most active one. Reactive oxygen species can be generated by the prooxidative enzyme, $\mathrm{XO}$, and the peroxidative enzyme, 15-LO, in vascular cells [31]. Components isolated from Aronia berries demonstrated inhibitory activity towards $15-\mathrm{LO}$ and $\mathrm{XO}$ and may have a potential to alleviate oxidative stress. Until recently, anthocyanins were believed to have a very low bioavailability, but it has been demonstrated that the bioavailability of anthocyanins was underestimated [32,33]. In addition, anthocyanins are some of the few polyphenols that can be detected unmetabolized (e.g., as glycosides) in plasma [32]. It has to be taken into consideration that the bioavailability of flavanols varies depending on the degree of polymerization. Low molecular weight oligomeric procyanidins $(\mathrm{DP} \leq 3)$ are absorbed intact in the gastrointestinal tract, but polymerization greatly impairs intestinal absorption [32-34]. In order to act as 15-LO and XO inhibitors in vivo, constituents have to be absorbed from the gastrointestinal tract. In view of the known bioavailability of tested compounds, Aronia products and extracts containing anthocyanins and oligomeric procyanidins $(\mathrm{DP} \leq 3)$ may have biologically relevant 15 -LO and XO effects. Inhibition of $\alpha$-glucosidase delays carbohydrate digestion and the absorption of monosaccharides from the intestine [16]. Fractions enriched in procyanidins, the purified procyanidins and anthocyanins from A. melanocarpa berries were potent $\alpha$-glucosidase inhibitors, suggesting that they may have beneficial effects in reducing blood glucose level. In order to act as $\alpha$-glucosidase inhibitors in vivo, compounds do not have to be absorbed from the gastrointestinal tract, since it is a membrane-bound enzyme located at the epithelium of the small intestine [20]. Therefore, anthocyanins and procyanidins with even a high degree of polymerization may exert local effects in the gastrointestinal tract as $\alpha$-glucosidase inhibitors.

\section{Conclusions}

We have shown that some extracts, fractions and constituents from A. melanocarpa possess activity of potential health benefits as radical scavengers, 15-LO inhibitors, XO inhibitors and $\alpha$-glucosidase inhibitors in vitro. The difference in activity between the trimeric procyanidin $\mathrm{C} 1$ and the dimeric procyanidins B2 and B5 has, to our knowledge, not been reported previously. Also, it was found that the activity seems to be influenced by the sugar units linked to the anthocyanidin. No systematic investigations of A. melanocarpa extracts and fractions as radical scavengers, 15-LO inhibitors, XO inhibitors and $\alpha$-glucosidase inhibitors has been reported previously. The activities of these extracts, fractions and compounds in vivo would seem to be an important subject for further research. The presence of biologically active compounds in Aronia berries increases the nutritional value of this 
plant, as a rich source of radical scavengers and inhibitors of peroxidative and prooxidative enzymes (15-LO, XO) and of $\alpha$-glucosidase, an enzyme which may be involved in diabetes. This would appear to be of interest to the food industry.

\section{Acknowledgments}

This work was financially supported by the Research Council of Norway and Tine SA under project number 190402/I10. The NMR laboratory of the Chemistry Department, University of Oslo, is acknowledged for the spectrometer facilities.

\section{Conflict of Interest}

The authors declare no conflict of interest.

\section{References}

1. Kokotkiewicz, A.; Jaremicz, Z.; Luczkiewicz, M. Aronia plants: A review of traditional use, biological activities, and perspectives for modern medicine. J. Med. Food 2010, 13, 255-269.

2. Kulling, S.E.; Rawel, H.M. Chokeberry (Aronia melanocarpa)-A review on the characteristic components and potential health effects. Planta Med. 2008, 74, 1625-1634.

3. Oszmiański, J.; Wojdylo, A. Aronia melanocarpa phenolics and their antioxidant activity. Eur. Food Res. Technol. 2005, 221, 809-813.

4. Zheng, W.; Wang, S.Y. Oxygen radical absorbing capacity of phenolics in blueberries, cranberries, chokeberries, and lingonberries. J. Agric. Food Chem. 2003, 51, 502-509.

5. Roobha, J.J.; Saravanakumar, M.; Aravinthan, K.M.; Devi, S.P. Antioxidant analysis of anthocyanin extracted from Musa acuminata bract. J. Pharm. Res. 2011, 4, 1488-1492.

6. Yao, Y.; Sang, W.; Zhou, M.; Ren, G. Antioxidant and $\alpha$-glucosidase inhibitory activity of colored grains in China. J. Agric. Food Chem. 2010, 58, 770-774.

7. Mansouri, E.; Panahi, M.; Ghaffari, M.A.; Ghorbani, A. Effects of grape seed proanthocyanidin extract on oxidative stress and antioxidant enzymes in kidney of rats with diabetic nephropathy. Rom. J. Biophys. 2011, 21, 243-252.

8. Kumar, B.; Gupta, S.K.; Nag, T.C.; Srivastava, S.; Saxena, R. Green tea prevents hyperglycemia-induced retinal oxidative stress and inflammation in streptozotocin-induced diabetic rats. Ophthalmic Res. 2012, 47, 103-108.

9. Calabrese, V.; Cornelius, C.; Leso, V.; Trovato-Salinaro, A.; Ventimiglia, B.; Cavallaro, M.; Scuto, M.; Rizza, S.; Zanoli, L.; Neri, S.; Castellino, P. Oxidative stress, glutathione status, sirtuin and cellular stress response in type 2 diabetes. Biochim. Biophys. Acta Mol. Basis Dis. 2012, $1822,729-736$.

10. Naudi, A.; Jove, M.; Ayala, V.; Cassanye, A.; Serrano, J.; Gonzalo, H.; Boada, J.; Prat, J.; Portero-Otin, M.; Pamplona, R. Cellular dysfunction in diabetes as maladaptive response to mitochondrial oxidative stress. Exp. Diabetes Res. 2012, doi:10.1155/2012/696215.

11. Li, F.; Tang, H.; Xiao, F.; Gong, J.; Peng, Y.; Meng, X. Protective effect of Salidroside from Rhodiolae radix on diabetes-induced oxidative stress in mice. Molecules 2011, 16, 9912-9924. 
12. Dobrian, A.D.; Lieb, D.C.; Cole, B.K.; Fishwick, D.A.T.; Chakrabarti, S.K.; Nadler, J.L. Functional and pathological roles of the 12- and 15-lipoxygenases. Prog. Lipid Res. 2011, 50, 115-131.

13. Pacher, P.; Nivorozhkin, A.; Szabó, C. Therapeutic effects of xanthine oxidase inhibitors: Renaissance half a century after the discovery of allopurinol. Pharmacol. Rev. 2006, 58, 87-114.

14. Simeonov, S.B.; Botushanov, N.P.; Karahanian, E.B.; Pavlova, M.B.; Husianitis, H.K.; Troev, D.M. Effects of Aronia melanocarpa juice as part of the dietary regimen in patients with diabetes mellitus. Folia Med. (Plovdiv) 2002, 44, 20-23.

15. Valcheva-Kuzmanova, S.; Kuzmanov, K.; Tancheva, S.; Belcheva, A. Hypoglycemic and hypolipidemic effects of Aronia melanocarpa fruit juice in streptozotocin-induced diabetic rats. Methods Find. Exp. Clin. Pharmacol. 2007, 29, 101-105.

16. Adisakwattana, S.; Yibchok-Anun, S.; Charoenlertkul, P.; Wongsasiripat, N. Cyanidin-3-rutinoside alleviates postprandial hyperglycemia and its synergism with acarbose by inhibition of intestinal a-glucosidase. J. Clin. Biochem. Nutr. 2011, 49, 36-41.

17. Slimestad, R.; Torskangerpoll, K.; Nateland, H.S.; Johannessen, T.; Giske, N.H. Flavonoids from black chokeberries, Aronia melanocarpa. J. Food Comp. Anal. 2005, 18, 61-68.

18. Wangensteen, H.; Samuelsen, A.B.; Malterud, K.E. Antioxidant activity in extracts from coriander. Food Chem. 2004, 88, 293-297.

19. Noro, T.; Oda, Y.; Miyase, T.; Ueno, A.; Fukushima, S. Inhibitors of xanthine oxidase from the flowers and buds of Daphne genkwa. Chem. Pharm. Bull. 1983, 31, 3984-3987.

20. Matsui, T.; Yoshimoto, C.; Osajima, K.; Oki, T.; Osajima, Y. In vitro survey of $\alpha$-glucosidase inhibitory food components. Biosci. Biotechnol. Biochem. 1996, 60, 2019-2022.

21. Kandil, F.E.; Song, L.; Pezzuto, J.M.; Marley, K.; Seigler, D.S.; Smith, M.A.L. Isolation of oligomeric proanthocyanidins from flavonoid-producing cell cultures. In Vitro Cell. Dev. Biol. Plant 2000, 36, 492-500.

22. Eberhardt, T.L.; Young, R.A. Conifer seed cone proanthocyanidin polymers: Characterization by ${ }^{13} \mathrm{C}$ NMR spectroscopy and determination of antifungal activities. J. Agric. Food Chem. 1994, 42, 1704-1708.

23. Wangensteen, H.; Dang, H.C.T.; Uddin, S.J.; Alamgir, M.; Malterud, K.E. Antioxidant and antimicrobial effects of the mangrove tree Heritiera fomes. Nat. Prod. Commun. 2009, 4, 371-376.

24. Villaño, D.; Fernández-Pachón, M.S.; Moyá, M.L.; Troncoso, A.M.; García-Parrilla, M.C. Radical scavenging ability of polyphenolic compounds towards DPPH free radical. Talanta 2007, 71, 230-235.

25. Kähkönen, M.; Heinonen, M. Antioxidant activity of anthocyanins and their aglycons. J. Agric. Food Chem. 2003, 51, 628-633.

26. Matsui, T.; Ueda, T.; Oki., T.; Sugita, K.; Terahara, N.; Matsumoto, K. $\alpha$-Glucosidase inhibitory action of natural acylated anthocyanins. 1. Survey of natural pigments with potent inhibitory activity. J. Agric. Food Chem. 2001, 49, 1948-1951.

27. McDougall, G.; Shpiro, F.; Dobson, P.; Smith, P.; Blake, A.; Stewart, D. Different polyphenolic components of soft fruits inhibit $\alpha$-amylase and $\alpha$-glucosidase. J. Agric. Food Chem. 2005, 53, 2760-2766. 
28. Kumar, S.; Narwal, S.; Kumar, V.; Prakash, O. $\alpha$-Glucosidase inhibitors from plants: A natural approach to treat diabetes. Pharmacogn. Rev. 2011, 5, 19-29.

29. Ma, C.-M.; Sato, N.; Li, X.-Y.; Nakamura, N.; Hattori, M. Flavan-3-ol contents, anti-oxidative and $\alpha$-glucosidase inhibitory activities of Cynomorium songaricum. Food Chem. 2010, 118, 116-119.

30. Knaup, B.; Oehme, A.; Valotis, A.; Schreier, P. Anthocyanins as lipoxygenase inhibitors. Mol. Nutr. Food Res. 2009, 53, 617-624.

31. Madamanchi, N.R.; Vendrov, A.; Runge, M. Oxidative stress and vascular disease. Arterioscler. Thromb. Vasc. Biol. 2005, 25, 29-38.

32. Pascual-Teresa, S.; Moreno, D.A.; García-Viguera, C. Flavanols and anthocyanins in cardiovascular health: A review of current evidence. Int. J. Mol. Sci. 2010, 11, 1679-1703.

33. Manach, C.; Williamson, G.; Morand, C.; Scalbert, A.; Rémésy, C. Bioavailability and bioefficacy of polyphenols in humans. I. Review of 97 bioavailability studies. Am. J. Clin. Nutr. 2005, 81, 230-242.

34. Rasmussen, S.E.; Frederiksen, H.; Krogholm, K.S.; Poulsen, L. Dietary proanthocyanidins: Occurrence, dietary intake, bioavailability, and protection against cardiovascular disease. Mol. Nutr. Food Res. 2005, 49, 159-174.

(C) 2013 by the authors; licensee MDPI, Basel, Switzerland. This article is an open access article distributed under the terms and conditions of the Creative Commons Attribution license (http://creativecommons.org/licenses/by/3.0/). 